\title{
LÉXICO DE LA VIVIENDA EN EL ESPAÑOL CENTROAMERICANO
}

\author{
Miguel Ángel Quesada Pacheco
}

\section{(c) $(7)(9)$}

Esta obra está bajo una licencia Creative Commons 



\title{
LÉXICO DE LA VIVIENDA EN EL ESPAÑOL CENTROAMERICANO
}

\author{
LEXICON FOR HOUSEHOLD ITEMS IN CENTRAL \\ AMERICAN SPANISH
}

\author{
Miguel Ángel Quesada Pacheco
}

\begin{abstract}
RESUMEN
El presente es un trabajo empírico de carácter dialectal, semántico y etnolingüístico, el cual describe y analiza vocablos relacionados con el mundo de la vivienda en el español centroamericano. El estudio se basa en el conjunto de datos recopilados en los atlas lingüístico-etnográficos de Belice, Guatemala, El Salvador, Honduras, Nicaragua, Costa Rica y Panamá.

El análisis permite afirmar que, por lo general, los centroamericanos organizan y categorizan el léxico de la vivienda de manera diferente a como se da en el español estándar.

Palabras clave: Lingüística, español centroamericano, lexicografía, vivienda, etnolingüística.
\end{abstract}

\begin{abstract}
The present article is an empirical study of dialectal, semantic and ethno-linguistic character, which describes and analyzes words related to the world of housing in Central-American Spanish. The study is based on data collected from the linguistic-ethnographic atlases of Belize, Guatemala, El Salvador, Honduras, Nicaragua, Costa Rica and Panama.

The analysis proves that, generally, Central-Americans organize and categorize the lexicon of housing in a different way as given in standard Spanish.

Key words: Linguistics, Central-American Spanish, Lexicography, Housing, Ethno-linguistics.
\end{abstract}

\section{Introducción}

El presente estudio analiza ciertos rasgos referentes a la manera como imaginan y perciben los centroamericanos el campo léxico de la vivienda, sin dejar de lado los mecanismos lingüísticos y culturales que emplean para sus definiciones y categorizaciones. En este sentido, el estudio se enmarca dentro del dominio de la llamada etnolingüística o antropología lingüística, tal como lo observa Riley: “[T]he study of a group's experience of life as it is

Dr. Miguel Ángel Quesada Pacheco. Profesor de la Universidad de Costa Rica y de la Universidad de Bergen (Noruega). Costa Rica.

Correo electrónico: miguel.pacheco@uib.no

Recepción: 28- 08- 2016

Aceptación: 07- 02- 2017 
organized and expressed through the group's language tools and as a science whose aim is to examine the relationships between a language on the one hand and society and culture on the other" (Riley, 2007, p. 8).

Este trabajo, el cual es parte de un proyecto que estudia y analiza ciertos rasgos lingüísticos y culturales del español centroamericano, toma como base los corpus de los atlas lingüístico-etnográficos que se han venido publicando bajo el proyecto Variación lingüística de América Central, patrocinado por la Universidad de Bergen y la Fundación Meltzer. ${ }^{1}$

Si bien existen algunos estudios cortos que marcan cierto interés por la disciplina en América Central (por ejemplo Wande, 2003; Álvarez-Montalbán, 2004; García, 2004), lo cierto es que los estudios etnolingüísticos brillan por su ausencia en la investigación sobre el español centroamericano, con certeza debido a la falta de trabajos de campo, así como por el interés centrado en otras disciplinas lingüísticas, tales como la lexicografía tradicional $^{2}$ y la fonética (cfr. Quesada-Pacheco, 2008).

Varias ramas del saber se han ocupado de la relación entre lengua, pensamiento y cultura, tales como la etnosemántica, la etnografía de la comunicación, la llamada linguística boasiana y la antropología lingüística (cfr. Underhill, 2012, pp. 17-18). Respecto de la última, en general se hace uso de los conceptos etnolingüística y antropología lingüística en calidad de sinónimos (cfr. Duranti, 1997, p. 3; Riley, 2007, p. 8), de modo que cuando se estudia un determinado fenómeno cultural que esté relacionado con la lengua, puede llamársele indistintamente de una $\mathrm{u}$ otra forma.

Debido a que en sus inicios se trabajó sobre la base de lenguas desconocidas o poco conocidas científicamente, muchas veces se entiende por etnolingüística el trabajo realizado con lenguas minoritarias, con lo cual se deja de lado lenguas de gran número de hablantes, como es el caso de la lengua española. Algo similar hace notar Underhill en la lingüística anglosajona, en vista de la predilección de la etnolingüística por el estudio de lenguas amerindias:

\footnotetext{
In modern and contemporary linguistics, ethnolinguistics has little place. And if we look to the language system itself, we find that the term rarely appears en spoken English. The Corpus of Contemporary American (COCA) 410-million-word corpus provided only one reference to 'ethnolinguistics', a reference, predictably, to Amerindian language study, whereas 682 references were found for 'linguistics'. (Underhill, 2012, pp. 18-19)
}

Y a menos que esté escondida entre revistas o libros de poca difusión, a juzgar por la bibliografía consultada, particularmente la relativa al español centroamericano, se puede inferir que los estudios de esta índole son casi inexistentes. A lo anterior se suma el hecho de que, como afirma Dickeman (1982, p. 113), "La existencia de una relación entre lengua y cultura parece ser tan obvia, que no necesita ser reafirmada”. Quizás sea esta la razón por la cual no se haya despertado el correspondiente interés entre los lingüistas que emplean su lengua materna -en este caso el español- como objeto de estudio desde una perspectiva lingüístico-cultural, pero sí cuando se trata de estudios sobre lenguas menos conocidas.

De acuerdo con Mišić (2004, p. 3), la antropología lingüística se define en los siguientes términos: "Anthropological linguistics is usually what one first thinks of when talking about the relationship between language and culture. It studies language variation and use in relation to the cultural patterns and beliefs and relies heavily on theories, methods and findings of anthropology".

Como se puede observar, esta disciplina analiza la clasificación de una lengua a través del conocimiento universal y general del mundo, y a menudo se concentra en las manifestaciones culturales designadas por palabras, así como en la manera como estas palabras abordan las 
distintas características del quehacer humano. Dentro de la etnolingüística, el lenguaje no es solo un sistema de signos, sino también un conjunto de normas e ideologías acerca del lenguaje y de su uso, así como de los patrones que generan su creatividad (cfr. Risager, 2006, p. 34).

Muchas veces este conjunto de normas e ideologías pueden llevar a equívocos o confusiones, porque se afirman rasgos culturales o estereotipos debido a ciertas características estructurales de una lengua. Por ejemplo, y tal como lo pone Dickeman (1982, pp. 3-5), creer que los hispanohablantes son inseguros porque tienen el modo subjuntivo, con el cual se expresa duda o inseguridad. $\mathrm{O}$ bien, que los indios bribris ${ }^{3}$ no tienen sentido de la propiedad porque emplean el mismo verbo para expresar las acciones de 'dar' y de 'prestar'. Dickeman profundiza en el tema sacando a colación diversas relaciones que pueden ser las responsables de estas confusiones:

a) la relación asociativa, de acuerdo con la cual, un rasgo lingüístico específico aparece junto a un rasgo cultural específico;

b) relación causal, según la cual, es el rasgo lingüístico el que determina el rasgo cultural, y

c) relación implicacional, la cual determina que el rasgo lingüístico está supeditado al rasgo cultural.

Siguiendo a Foley (op. cit., 5 y ss.), la antropología lingüística busca los significados en prácticas lingüísticas dentro de una práctica cultural más amplia, y donde el término "cultura" se entiende como una red histórica de signos, o como una cadena de significados con sus formas expresadas de manera extrínseca (Foley, 2002, p. 15). ${ }^{4}$

Al igual que en trabajos anteriores (Quesada-Pacheco, 2011 y 2012), en el presente estudio se muestra el concepto de signo desde una perspectiva etnolingüística, y dentro de lo que G. Palmer (2000) llama postulados culturales: "Un postulado es simplemente una predicación verbal con imaginería cultural relativamente abstracta en su polo semántico" (Palmer, 2000, p. 135).

Respecto de la metodología seguida en el presente estudio, se extrajeron los datos concernientes a las 43 preguntas del cuestionario confeccionado para el Atlas lingüísticoetnográfico de Costa Rica (Quesada-Pacheco, 1992, pp. 29-30; ver Anexo), ${ }^{5}$ relativos al campo semántico de la vivienda, el cual se extendió a los atlas lingüístico-etnográficos de América Central; a saber, el de Belice o ALEB (Rivera-Orellana, 2013), de Guatemala o ALEG (Chavarría-Úbeda, manuscrito), de El Salvador o ALPES (Rivera-Orellana, 2011), de Honduras o ALEH (Ventura, 2013), de Nicaragua o ALEN (Chavarría-Úbeda y Rosales-Solís, 2010), de Costa Rica o ALECORI (Quesada- Pacheco, 2010) y de Panamá o ALEP (TinocoRodríguez, 2010). Se aplicaron las mismas preguntas a todos los países, con lo cual se logró una uniformidad de datos que permite estudiarlos en conjunto y de manera comparada.

Al realizar un estudio como el presente, con América Central como un conjunto cultural, no se quiere negar la autonomía que cada país tiene en la región, pues, tal como afirma M. Mayers:

\footnotetext{
Each nation within Latin America is quite distinct. Linguistic differences provide some of the lesser distinctions. People in Guatemala tend to be rural and provincial in outlook whereas those in Venezuela tend to be urban. South Americans tend to have more "church" awareness whereas those in Central America are less tied to the church and more narrowly religious. In Central America the strength of the extended family is quite noticeable, e.g., political control of El Salvador resides in a few families, whereas in South America this extreme focus on the extended family is moderated. (Mayers, 1997, p. 16)
}

$\mathrm{Y}$ al igual que en los estudios antes mencionados (Quesada-Pacheco, 2011 y 2012), en el presente caso lo que se quiere es buscar y analizar esquemas o procesos etnolingüísticos comunes a los centroamericanos de habla española dentro del campo etnosemántico de la 
vivienda, sin dejar de lado los rasgos culturales que cada nación pueda manejar por aparte. En algunos casos se harán comentarios de índole léxico-semántica.

Se recogió un total de 2852 entradas para las 43 preguntas que conforman el cuestionario relativo a la vivienda (Figura 1).

\begin{tabular}{|l|l|l|l|l|l|l|l|}
\hline País & BE & GU & ES & HO & NI & CR & PA \\
\hline Número de entradas & 240 & 386 & 381 & 545 & 329 & 533 & 438 \\
\hline Número de localidades entrevistadas & 12 & 22 & 20 & 18 & 17 & 36 & 18 \\
\hline
\end{tabular}

Figura 1. Léxico de la vivienda por país y número de localidades

Como se puede ver en la Figura 1, no hay relación sistemática entre el número de localidades entrevistadas y el número de entradas recogidas, pensando en que cuanto mayor fuera el número de puntos entrevistados, tanto mayor sería la cantidad de datos. Por ejemplo, en Costa Rica se entrevistaron 36 localidades, pero se obtuvo 533 palabras, mientras que en Honduras, con la mitad de puntos encuestados, se recopiló un poco más. Solo Belice, Guatemala, El Salvador y Nicaragua registran una cantidad de entradas que se podría relacionar con el número de puntos entrevistados. Luego, al eliminar las palabras que estaban repetidas, ${ }^{6}$ quedó un total de 920 entradas, con las cuales se trabajó el material que se explica a continuación.

Se debe aclarar que estas entradas no siempre se dieron en todos los países: algunas se registran en todos ellos, otras solamente en dos, otras en tres, y así sucesivamente. Sin embargo, dado que el carácter del presente estudio no es dialectal, no se especificará la proveniencia del término en cuestión, a menos que la descripción lo amerite. Así, en términos generales, cuando una unidad léxica no explicite su proveniencia, es porque se trata de un término común, o bien, extendido por dos o más países del Istmo.

\section{Análisis de los datos}

\subsection{Casa}

Al responder a lo que entendían por 'casa' (pregunta 1 del Cuestionario), o las palabras que se le daban para designar el edificio donde se habita, los informantes dieron una serie de voces sinonímicas comunes, tales como: hogar, vivienda, residencia, lugar de habitación, lugar donde convive una familia, posada y local; además de palabras menos comunes como choza, chante chanti y house. Por otra parte, tuvieron en cuenta la calidad del edificio, de modo que se pueden señalar dos tipos de vivienda según los datos:

1. Vivienda de bajos recursos: rancho y su atenuante ranchito, choza, galera, champa (El Salvador), cueva, bohío, jacal. ${ }^{7}$

2. Vivienda de altos recursos: mansión, palacio.

Como se puede observar, el grupo de palabras que designan viviendas de bajos recursos es el más numeroso; su explicación podría radicar en el alto nivel de pobreza del Istmo Centroamericano.

Por otra parte, prácticamente todas las palabras dadas apuntan a un edificio unifamiliar donde se habita; en consecuencia, llama la atención la ausencia de palabras que designan edificios o complejos multifamiliares de habitación (condominio, torre, etc.). Esto muy probablemente 
porque el centroamericano tiende a habitar en casas para una sola familia, independientes de las demás, sea en barrios, colonias o suburbios, y porque el tipo de vivienda multifamiliar suele ser muy caro y por lo tanto destinado a personas pudientes. ${ }^{8}$

\subsection{Materiales más comunes con que están construidas las viviendas de la comunidad}

Los materiales con los que están construidas las casas, nombrados por las personas entrevistadas (preguntas 2 y 3 del Cuestionario), ${ }^{9}$ se pueden clasificar en dos grupos: materiales extraídos de la naturaleza y materiales procesados o provenientes de las fábricas (Figura 2).

El primer grupo permite subdividirse en dos subgrupos:

a) materiales no elaborados o rudimentariamente elaborados (arcilla, barro, bejuco, cal, canto o piedra cantera, cascajo, costanera 'tipo de tabla', estiércol, grava, hojas de palmáceas como corozo, guágara, tique ${ }^{10}$ y suita, bambú, lodo, manaca, ocre, paja, penca, piedra, piedrín, piso de tierra, quincha, ${ }^{11}$ tierra embutida, varas, zacate) y

b) materiales elaborados (adobe, arena, asbesto, bajareque, baldosa, hierro, madera, teja).

En el grupo que tiene que ver con materiales procesados o provenientes de fábricas se pueden mencionar: ladrillo, cemento, lata, bloc o bloque, carriola, ${ }^{12}$ chingle, concreto, cuartón, duralita, durpanel, fibrolit, lámina metálica, nicalit, panalit, perling, plástico, plafond, ricalit, tejalit, varilla, vidrio y zinc.

La alta cantidad de nombres de materiales rudimentarios para la construcción de casas de habitación podría ser un indicio del bajo nivel de vida de muchos de los entrevistados.

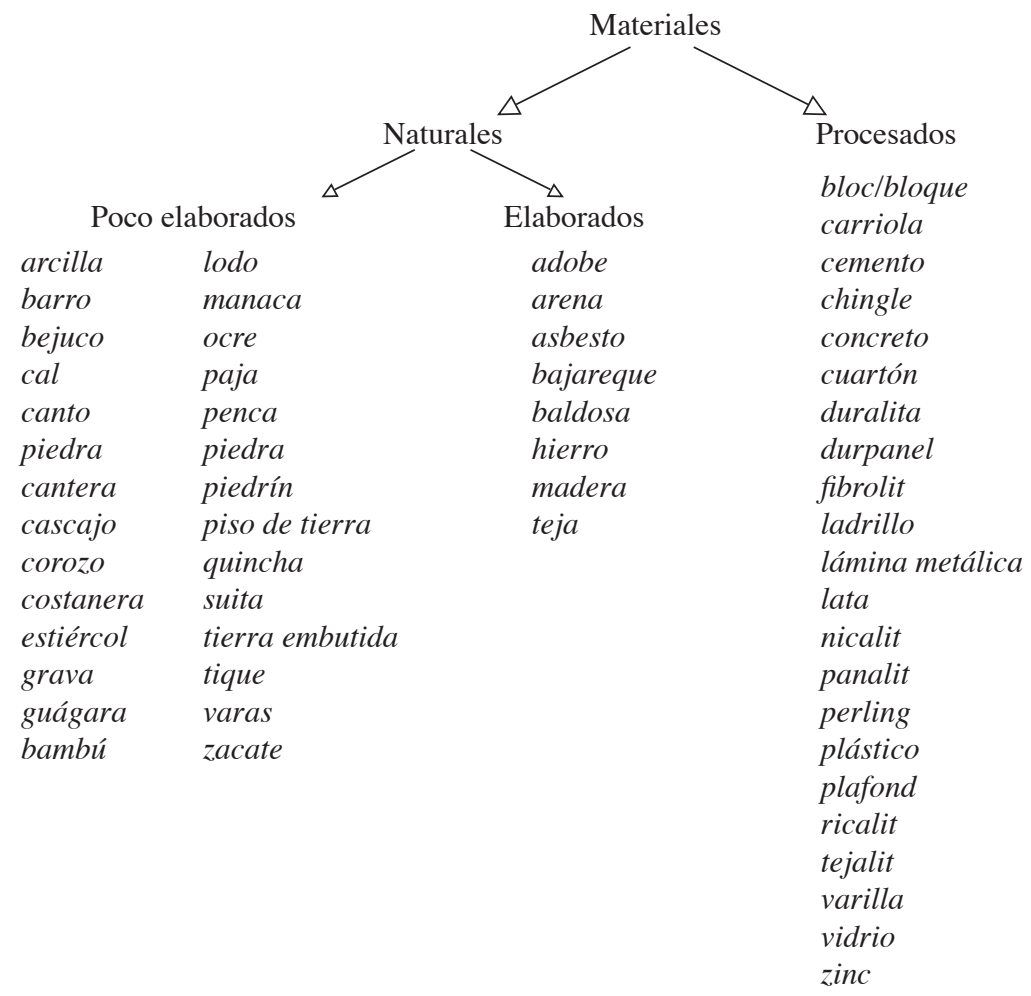

Figura 2. Materiales de que están construidas las casas de la comunidad 


\subsection{Tipos de techo y sus nombres}

En los nombres recopilados para los distintos tipos de techo (pregunta 4 del Cuestionario), los informantes apuntan a dos realidades: el material de que está hecho el tejado, y su forma.

Respecto del primer tipo, se señalan techos de madera, de fibra, de lámina y de palma, de zinc, de teja, de palmáceas; en resumen, aquellos que se fabrican con materiales naturales y aquellos fabricados con productos industriales.

En cuanto al segundo tipo, dominan cuatro variedades: el techo con un solo desliz de agua, el techo con doble desliz de agua, que son los más comunes; el techo con tres deslices y el que tiene cuatro deslices. Al techo con un solo desliz se le pueden considerar dos formas: una plana y la otra inclinada. A la forma plana le llaman terraza o terraza plana, techo plano, techo recto. A la inclinada le dicen: media agua, de una agua, de una corriente (en Honduras), un solo desliz de agua, desnivel, terraza inclinada.

El techo con doble desliz de aguas se llama: de dos aguas, doble agua, doble desliz de agua, dos caídas de agua, techo de tijera o tijera, techo en desnivel, o bien, estilo cabaña.

Al techo con tres deslices se le registró como pachuco (en Costa Rica) y pirámide (en Panamá).

Al último subtipo le llaman techo de cuatro aguas o de varias aguas, cuando las pendientes de los techos son numerosas.

No se registró el tipo de techo circular, que se puede apreciar en algunas comunidades indígenas del Istmo (como por ejemplo entre los bribris, los guaymíes y los antiguos huetares). Esto porque muy probablemente este tipo de techo no se emplee más que en dichas comunidades, las cuales quedaron exentas de investigación, dado que no manejaban el español como lengua materna.

\subsection{Partes del tejado}

En este apartado se consideraron las preguntas relativas a los nombres que se les dan a los siguientes elementos que conforman el tejado (preguntas 5-8 del Cuestionario): solera, caballete, armazón triangular sobre apoyos y las reglas sobre la armadura del tejado donde se clavan las tejas o las láminas.

Al preguntar por solera, los entrevistados confundieron el término con solar 'traspatio', por cuya causa se debieron eliminar casi todas las palabras asociadas a solar o patio. Quedaron las siguientes: caballete, caballete del tejado, sombrera, carriola, costanera, cuartón, cumbrera, madera del medio, mojinete, palo horizontal, palo que amarra la pared, paral, reglona, renglón, solera, sombra, viga, viga central, viga madre, viga principal. Aun más, hubo quienes aseguraron que solera era un alero, lo que sobresale del techo, un sobrante, algo fuera de la pared; esta traslación semántica se podría explicar por metonimia, aunque también existe la posibilidad de que no supieran definirla; de hecho, algunos informantes adujeron que no sabían qué era una solera.

De lo anterior se infiere que la palabra solera, al menos en el lenguaje común, ha diluido su semanticidad y hoy en día tiene varios significados, como se puede ver en el siguiente apartado.

En cuanto a caballete, se le dieron varios nombres, de entre los que sobresalen los siguientes: alfajía, arriostre, base, caballete, cañón, cargador, carriola, cercha, cuartón, 
cumbrera, espejo, esperlin, horcón, marco, mojinete, muerto, palo, péndula, polín, reglón de división, solera, soporte, tendilera, tijera, tirante, viga, viga corona y vigueta.

En lo pertinente a la armazón triangular sobre apoyos, para esta estructura se registraron las siguientes palabras: alfajía, angular, apoyo, armazón, artesón, base, caballete, caballo, caída, cercha, costanera, culata, cumbrera, escuadra, esquinero, estructura, hombrera, horcón, listón, marco, mojinete, morillo durmiente, palo, pilar, polín, solera, soporte, tijera, varilla y viga.

Nuevamente en este caso se registran palabras que resultan sinonímicas respecto de lo que es una solera y un caballete, desde el español estándar.

Por último, las palabras registradas para los maderos o reglas donde se clavan o sostienen las tejas o las láminas son: alfajilla, artesón, base, caballete, caballo, canal, cargalámina, cargazinc, carriola, cercha, cimbra, cinta, clavador, costanera, cuadro, cuartón, culata, cumbrera, enreglado, envarillado, fajilla, formaleta, lintel, listón, madero, morillo, paral, percha, perlin, ratonera, regla, regleta, reglón, solera, soporte, tijera, trozo, vara, varazón, varilla, viga.

A diferencia de los las denominaciones anteriores, en este se hallan nuevas palabras, tales como caballo, canal, cargalámina, cargazinc, cimbra, cinta, clavador, cuadro, enreglado, envarillado, lintel, percha, ratonera, regleta y varazón, de lo cual se infiere que esta parte del tejado se distingue del resto en cuanto a su estructura.

\subsection{Distribución de las casas}

La pregunta 9, relacionada con la distribución de las casas, permite acomodar las respuestas en dos grupos: a) distribución exterior de las casas, y b) distribución interior.

Las palabras recogidas en la primera sección apuntan a casas que tienen que ver con los centros urbanos, y no tanto con el mundo rural: se distribuyen por cuadras, seguidas, unidas, por calles, callejones y avenidas, en fila, por barrios, manzanas, colonias, caseríos o aldeas. En ningún momento los entrevistados se refirieron a casas en medios rurales, debido a que las encuestas se desarrollaron precisamente en centros urbanos del Istmo Centroamericano, en la mayor parte de los casos.

Respecto de la distribución interior, se señalaron las siguientes partes como división fundamental de la casa:

1. Pieza donde se estaciona el automóvil: cochera, porche.

2. Pieza delantera exterior: corredor, entrada, jardín, frente.

3. Sitio para descansar: sala, sala de recibo, sala grande.

4. Sitio para preparar los alimentos: cocina.

5. Sitio del aseo o higiene personal (pregunta 17). Dado el dominio del tabú en este aspecto, se dan dos tipos de palabras: disfemismos (cagadero) y eufemismos. Dentro de estos se distinguen dos grupos: los que tienen palabras neutras (baño, cloaca, escusado, inodoro, interior, letrina, orinal, sanitario, servicio, servicio higiénico, taza, tocador, toilet) y aquellas de carácter humorístico: cerco (Costa Rica), chele chele bocón (El Salvador), pompón (Nicaragua) y taburete (Panamá). Además, se señalan palabras que designan el servicio sanitario fuera de la casa, tales como baño de afuera, cerco (Costa Rica), escusado de hueco, fosa y hoyo. 
6. Parte trasera y descubierta de la casa (pregunta 16): encierro, entrepatio, finca, finca de atrás, huerta, huerto, jardín, patio, patio de salida, patio del fondo, patio trasero, sitio, solar, terraza, terreno, traspatio, yarda, zona verde.

7. Pieza para dormir (pregunta 14): aposento, cuarto, cuarto de dormir, dormitorio, habitación, recámara. Solamente Honduras registra chimadero y Panamá jorón, como voces particulares.

8. Pieza donde se consumen los alimentos: comedor.

9. Pieza donde se lava: cuarto de pilas, patio de pilas, lavadero o lavandero.

10. Pieza para almacenar objetos y cosas viejas (pregunta 15$):{ }^{13}$ almacén, ático, bodega, bodegón, bodeguilla, chilimico (Panamá), chiquero, chunchero, cuartillo, cuarto, cuarto de los chunches, cuarto viejo, depósito, galera, galerón, sótano, tapanco y troja. Algunos informantes dijeron que no usaban tal pieza o no la tenían en su casa, y por lo tanto no le conocían el nombre.

11. Sitio que une las piezas interiores: pasadizo.

Los datos anteriores permiten concluir que el prototipo de casa descrita por los entrevistados tiende a ser un lugar de habitación característico de una ciudad o comunidad urbana centroamericana. ${ }^{14}$ No se tomaron en cuenta las divisiones que podrían observarse en casas rurales, que podrían ser diferentes de las urbanas por sus espacios abiertos, por sus estructuras quizá más sencillas, o por piezas que por lo general en este tipo de casas están fuera de la estructura principal (cocina, lugares para almacenar herramientas, servicio sanitario exterior, etc.). Tampoco se recogieron datos relativos a otros planos de una casa, como planta alta, segundo piso, buhardilla, alcoba, etc., por lo demás, partes que no son al parecer comunes dentro del sistema de vivienda centroamericano.

\subsection{Grada ante la puerta de la calle}

Para esta pregunta (la 10 del Cuestionario) se registraron las siguientes respuestas: andén, batiente, ${ }^{15}$ entradero, escalera, escalerita, escalón, grada, grada de enfrente, grada de entrada, grada frontal, gradita, peldaño, quicio, umbral y vergüenza de la puerta. De los datos anteriores se infiere que los informantes prácticamente solo dieron palabras sinonímicas.

\section{7 'Cerradura' y 'cerrar con llave'}

En la pregunta 11, concerniente al cierre de una puerta, a la que se le puede echar la llave, se recogieron los siguientes nombres: candado, cerradura, cerrojo, chapa, chavín, llavín, pasador, picaporte, seguro y tranca.

Como nota de carácter dialectal, se registra la palabra chapa en la parte norte de América Central (Belice, Guatemala y El Salvador), mientras que llavín se registra en Honduras, Nicaragua y Costa Rica. El resto de las palabras se muestra en casi todos los países, sin distinción espacial.

En lo tocante al acto de cerrar con llave (pregunta 12), casi todas las respuestas aluden o remiten a la palabra llave: enllavar, cerrar con (doble) llave, echar (doble) llave, y meter/ pasar/poner (doble) llave. De las palabras anteriores solo destaca el verbo enllavar, empleado en toda América Central, menos en la parte central de Costa Rica y, al menos en los datos recopilados, en Panamá. El resto de las expresiones se registra en todos o casi todos los países. 
Otras palabras o expresiones sinonímicas son: asegurar, cerrar, echar (doble) pasador, poner seguro y trancar.

\subsection{Palo que a veces se pone detrás de la puerta, para cerrar}

La pregunta 13 del Cuestionario corresponde al palo que, colocándose de manera horizontal detrás de una puerta, sirve para asegurar su cierre. Para este modo de cerrar, al parecer relativamente desconocido, se registró un caudal de voces que sugiere lo contrario; es decir, que es bastante empleado: barrote, crucero, cruceta, cuartón, cuña, garrote, macheta, madero, palanca, palo, paral, pasador, pasatranca, patiente, pie de amigo, platina, puntal, regla, tabla, trampa, tranca, trancador, tranquera, travesaño, tronca, troncón, trozo, tubo, vergüenza, viga.

Respecto de su distribución espacial, Costa Rica sobresale por la cantidad de sinónimos dados a este palo, que no se registran en otros países del área: garrote, pasatranca, pie de amigo, platina, tranquera y tubo. Asimismo, Panamá destaca por las palabras barrote, palanca, patiente, trampa y vergüenza. El resto de las voces mencionadas en el párrafo anterior se registran en los demás países, de modo que se puede hacer una división espacial condicionada por la extensión geográfica de las unidades léxicas:

a) Costa Rica con un cúmulo de palabras que no se registran en otros países;

b) Panamá con la misma característica, y

c) el resto de América Central (Belice, Guatemala, El Salvador, Honduras y Nicaragua).

\subsection{Clases y formas de los asientos}

En las respuestas acumuladas en esta pregunta (la 18 del Cuestionario), se eliminaron aquellas palabras que no dieron mayores especificaciones (asiento, asiento con aberturas, asiento con apoyo, asiento corto, asiento grande, asiento ovalado, etc.), o que no se ajustaban a la pregunta (cojín, horqueta, horquilla, etc.), y se dejaron aquellas con las siguientes características: a) material de que está hecho el asiento; b) variedad de asientos.

Respecto del primer subgrupo, los entrevistados señalaron las siguientes características, entre las cuales sobresale el material de que está hecho el mueble para sentarse: asiento cuadrado, asiento de cuatro patas, asiento de cemento, asiento de fibra, asiento de hierro (para terrazas), asiento de madera, asiento de metal, asiento de plástico, asiento de porcelana, asiento individual, asiento junqueado o de junco, asiento largo, asiento ovalado, asiento pequeño, asiento redondo, asiento sin apoyo, asiento sin tornear, asiento torneado, asiento con espuma.

En lo referente a la variedad del mueble para sentarse, tenemos aquellos en que caben varias personas (banca escaño, sofá o mueble de sala, poyo), y aquellos en que cabe solo una persona. Entre estos, hay aquellos que permiten mecerse (abuelita, mecedora, silla abuelita) o recostarse (perezosa, silleta) y aquellos fijos. Dentro de los fijos, están los que tienen respaldar (butaca, silla, sillón, taburete taurete, tapesquito) y los que no lo tienen. Entre estos, se hallan aquellos de cuatro patas (banco, banquillo, butaco) y de tres patas (pata de gallina, zancudo) (Figura 3). 


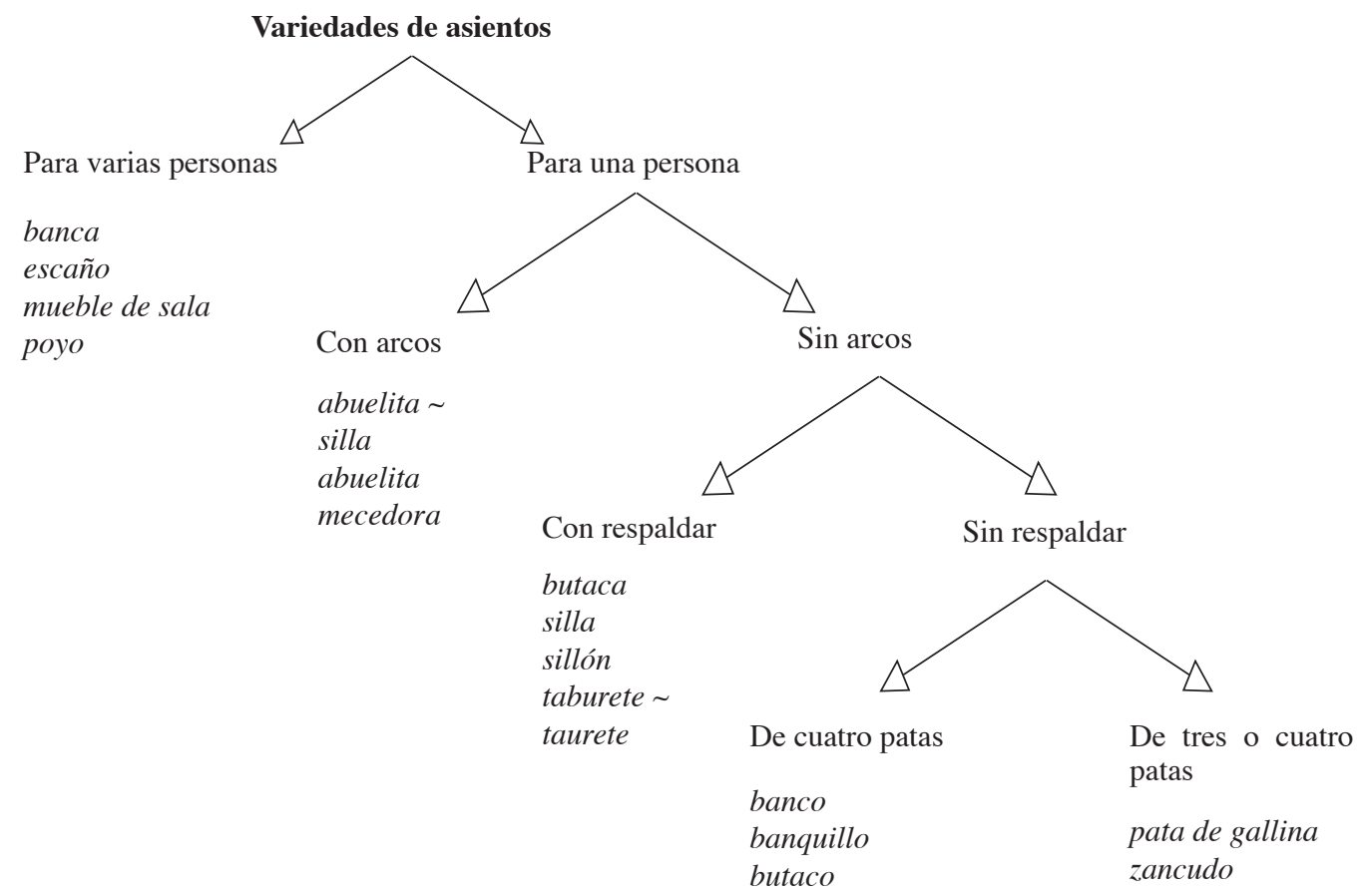

Figura 3. Variedades de asientos

\subsection{Muebles o sitios en los que se guardan los víveres}

La cantidad de datos recogida en este apartado, que corresponde a la pregunta 20 del Cuestionario, permite dividirlos en dos categorías: recipientes y armarios. Los recipientes son cualquier pieza cóncava o con espacio interior que sea susceptible de ser empleada como almacenadora de alimentos. Llama la atención la relativa cantidad de objetos aquí mencionada: baldes, barriles, baúles, ollas, panas (en Nicaragua) y otros recipientes, los cuales, según Carmen Chavarría Úbeda, ${ }^{16}$ responden a la pobreza de nuestros pueblos, donde la gente, al no tener acceso a sitios más complejos de almacenamiento de víveres, emplea cualquier cosa para conservarlos.

Por su parte, los armarios se pueden subdividir en dos grupos: sitios fijos de almacenamiento y sitios movibles. De entre los fijos surgen dos subcategorías: aquellos que están en el interior de una casa y los que se encuentran fuera, al aire libre.

En lo referente a los sitios movibles para almacenar víveres, se trata de cualquier tipo de escaparate que se coloca en la cocina, en el comedor y a veces en las salas, donde también se guardan utensilios para comer (Figura 4). 


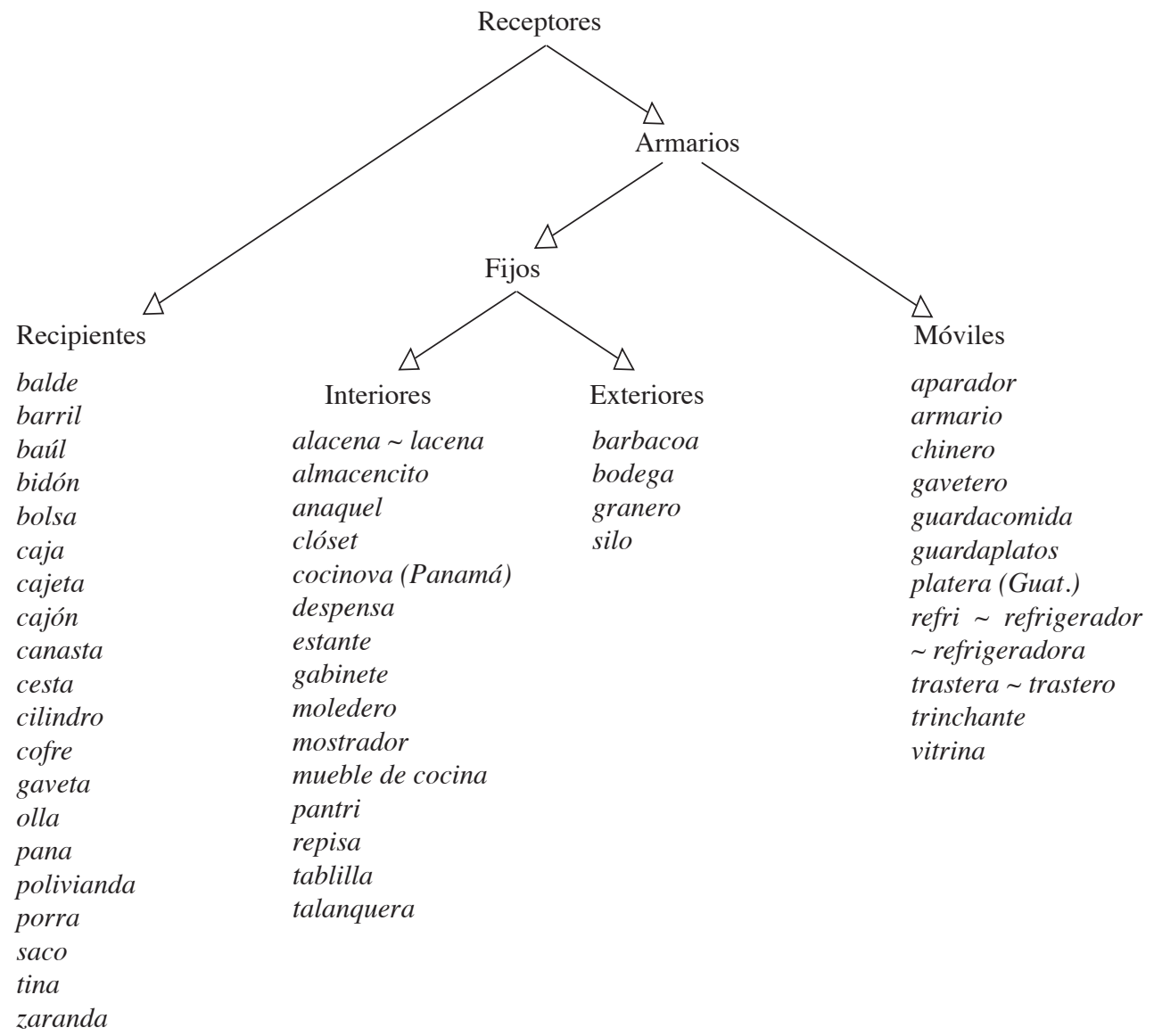

Figura 4. Muebles o sitios para almacenar víveres

\subsection{Muebles de cocina donde se preparan los alimentos antes de cocinarlos}

Los datos que dan los entrevistados para esta pregunta -la 21 del Cuestionariose pueden dividir en dos grupos: muebles, casi todos empotrados, que sirven para otros menesteres en la cocina, además de preparar alimentos. Estos son: artesa, banco, barbacoa, cocinova, desayunador, fregadero fregador, hornilla, lavaplatos, mesa $\sim$ mesa de cocina, mesilla, mesón, moledero molendero, mostrador, mueble de cocina, pantri, pila, poyetón (El Salvador), talanquera, tapesco (Honduras). En El Salvador, y de acuerdo con Romero (2005, p. 294), el poyetón es "Especie de mesa gruesa y rústica, en los hogares del campo, hecha de lodo sobre varas o cañas o con adobes, para poner en ella las hornillas donde se cocinan los alimentos". En Honduras, y según Bentley (2001, p. 145), el tapesco es una estructura similar a una cama de rejas o varas, empleada en las casas para guardar cosas; en el oriente salvadoreño, colindando con Honduras, es una mesa rústica hecha de varas o rejas (Romero, 2005, p. 331).

El otro grupo se refiere a una pieza plana, por lo general de madera, aunque también puede ser de plástico, la cual sirve para la preparación de los alimentos antes de ponerlos a cocinar (pelar, cortar, etc.). Se registraron las siguientes palabras: picador, tabla $\sim$ tabla de picar, tablero, tablita, tablón y trozo de madera. 


\subsection{Muebles o sitios donde se guarda la vajilla, y ¿qué se entiende por 'vajilla'?}

Los datos recopilados en la pregunta 22 permiten entrever que en la mayoría de las casas centroamericanas se emplean armarios o muebles, sean de madera o de metal, con divisiones abajo para guardar platos, vasos, tazas, y demás, así como alimentos, y con puertas, sean de madera (abajo) como de cristal (arriba). En la parte de arriba de estos armarios se guardan casi siempre los platos, los vasos, las tazas y otros utensilios para comer, menos víveres. A estos muebles se les llama: aparador, armario, chinero (fabricado en madera o en metal), cocinova, gabineta $\sim$ gabinete, gavetero, guardaloza, mueble aéreo, pantri, platera $\sim$ platero, trastera, trastero, trinchante, vidriera y vitrina.

Otros lugares que sirven a los centroamericanos para guardar la vajilla son sitios donde se combina el almacenamiento de utensilios con los alimentos: alacena $\sim$ lacena, barbacoa, caja, cajón, cajón de pantri, cajoncito, despensa, escurridor, estante, hierro, mesa (de madera empotrada en la pared), pana con tapa, poyetón, repisa, tablilla, tablillera, tablillero, talanquera y tina.

A la pregunta 22, referente a lo que se entiende por 'vajilla', las respuestas fueron casi unívocas: los centroamericanos entienden por vajilla el conjunto de platos, tazas, vasos, conocidos regionalmente como trastos o trastes (sea del material que sea: plástico, porcelana, loza, china, etc.) que se emplean para consumir los alimentos, y los llaman con las siguientes palabras: vajilla, trastes $\sim$ trastos, juego de trastos $\sim$ trastes, loza $\sim$ juego de loza y platería.

\subsection{Utensilio con que se come}

Los utensilios con los que se come, señalados por los entrevistados (pregunta 23), se pueden dividir en dos grupos: aquellos que son parte del cuerpo y aquellos que, en palabras de Mc Luhan (1964), ${ }^{17}$ son extensiones de nuestro cuerpo.

Los que son parte del cuerpo tienen que ver con las manos y los dedos, los cuales son empleados por muchos para comer. ${ }^{18}$ El resto tiene que ver con utensilios traídos por los europeos a América Central, como son: cuchillo (llamado también cubierto) y empleado para cortar los alimentos; cuchara, cucharita, plato, sopera (cuchara grande) y tenedor, también llamado trinchante, trinche o trinchete en la sección norte de América Central, desde Guatemala hasta Nicaragua.

Además, se recogieron algunas palabras de uso metafórico, a veces irónico, tales como bacenilla (Nicaragua) 'plato grande', herramientas (Costa Rica) 'cubiertos' y pala (Nicaragua) 'cuchara'.

\subsection{Utensilio en que se bebe}

Básicamente hay dos categorías de recipientes para beber (pregunta 24): aquellos elaborados con artefactos naturales, y aquellos elaborados industrialmente. Para los primeros tenemos recipientes hechos con el fruto del árbol bignoniáceo llamado morro en El Salvador y jícaro en el resto del Istmo (Crescentia cujete): calabazo, cumbita cumbito, guacal, jicara, totuma (Panamá). Otro recipiente natural es el coco, fruto del cocotero (Cocos nucifera), el cual, por su corteza dura, se puede dividir en dos mitades.

En cuanto a los recipientes elaborados industrialmente, están: copa, jarra, jarro, pichel, pichinga, pocillo, servidora (Guatemala) ${ }_{1}^{19}$ tagua (Panamá), taza, tinaja, vaso. En Guatemala 
mencionaron peila, un plato pequeño en que se coloca la taza de café o té, pues muchas personas han tenido la costumbre de verter el contenido caliente en dicho platito para enfriarlo y de allí beberlo.

\subsection{Cuchillos}

El Cuestionario de los atlas lingüísticos comprendía dos preguntas -25 y 26- para el instrumento para cortar, empleado en las labores de la cocina para la preparación de alimentos, y el empleado para comer. Las palabras recopiladas para el cuchillo de cocina son, acomodadas según su origen:

a) nombre común: cocinero, cuchillo, cuchillo de cocina, cuchillo de mango, cuchillo de palo, cuchillo grande

b) cuta, cutacha (de cutuche 'cortado')

c) espadín (de espada)

d) hachita, hachuela (de hacha)

e) macheta, machete

f) mochuelito (de origen desconocido)

g) navajo (de navaja)

h) puñal, puñal de cocina

i) retincillo (Costa Rica, de origen desconocido)

j) rola, rula (de origen desconocido)

k) sierra

Respecto del cuchillo para comer, se registraron las siguientes:

a) cuchillito, cuchillo, cuchillo chico o pequeño, cuchillo de comer, cuchillo de cubierta, cuchillo de mesa, cuchillo mesero, cuchillo pequeño

b) cubierto

c) puñal de mesa

d) serrucho, sierra

\subsection{Utensilios colgantes para preservar alimentos}

Las palabras recogidas en la pregunta 27 del Cuestionario permiten trazar varias categorías de instrumentos colgantes con los que se almacenan los alimentos, según la forma del objeto en cuestión:

a) armazones o plataformas colgantes del techo: cacaste, guardera (i. e.: gualdera), parrilla, salzo sarzo (de madera o de metal), tapesque.

b) cuerdas o similares: alambre, cabellos entrelazados, lazo, mecate, paral, pita.

c) recipientes: cafetera, frutera $\sim$ frutero, olla, perol, portavianda.

d) bolsos: alforja, bolsa, cebadera, chácara (Panamá), matate (El Salvador), salbeque.

e) cestería: canasta, canastera, canasto, cesta, cesto, jaba, motete (Panamá), ${ }^{20}$ red.

f) instrumentos corvos y puntiagudos: gancho, garabato, percha.

g) otros: armarrápido, asador, cedazo, clavo, colador, yagual, zaranda. 


\subsection{Tipos de cocina}

Los datos que se extrajeron de la pregunta 28 permiten dividir los aparatos para cocinar o guisar en tres categorías:

a) Aparatos que cocinan con fuego: cocinero (Nicaragua), fogón,fogonero, poyetón (Guatemala, El Salvador), cocina de caña (Panamá), cocina de leña, cocina de carbón, cocina de hierro. b) Aparatos que cocinan con combustible: cocina de gas, ${ }^{21}$ estufa, anafre, cocina de canfín, cocina de kerosén, cocina de quemadores.

c) Aparatos que cocinan con electricidad: cocina eléctrica, plantilla.

Como se puede observar, la cantidad de palabras que designan aparatos que cocinan con fuego o gas domina el panorama, quizás por lo costoso que es para un centroamericano de clase media o media baja comprar un aparato eléctrico, y también por lo caro de la electricidad en la región. ${ }^{22}$

\subsection{Piedras del fogón}

Los datos de la pregunta 19 apuntan a las siguientes palabras para designar las piedras que forman un fogón: piedra, tinamaste tenamaste.

Pero no solo las piedras se emplean para formar el fogón; también salieron a relucir materiales como: adobe, barro, bloque, ladrillo, tetunte (en Guatemala y El Salvador, 'trozo de ladrillo'), tierra o pedazos de cemento, y hasta hierros.

Algunos informantes aseguraron que en su localidad no se usan tales piedras para cocinar, y otros no reconocieron un nombre específico para ellas. De esto se infiere que el sistema de cocinar, empleando piedras para el fogón, está en varias partes del Istmo en estado de obsolescencia.

\subsection{Instrumentos para avivar el fuego}

De esta pregunta (la 30 del Cuestionario), surgieron dos tipos de datos: aquellos que se emplean para soplar, y los que se usan para combustión.

Los primeros se subdividen en dos grupos: aquellos especializados en soplar, tales como abanico, atizador, plumero, sopladero, soplador o soplete, y cualquier objeto que sirva para ese fin, como los siguientes: carrizos, cartones, gorras, mangueras, paletas, palmas, papel, platos, sombreros, tapaderas o tapas, ${ }^{23}$ o bien, cualquier cosa plana. Otros señalaron medios corporales para avivar, tales como la boca.

De nuevo aquí se puede deducir que, debido a la falta de medios económicos para conseguir un aparato especial para soplar, los centroamericanos se dan a la tarea de buscar cualquier cosa para avivar el fuego.

En lo concerniente a medios usados en combustión, señalaron los siguientes: alcohol, astillas, canfín, cera, diesel, fósforos, gas, leña, (Honduras) ocote en hilachones, olotes ('corozo o centro de una mazorca, donde se adhieren los granos de maíz'), plástico, querosene, resina, tizones y tusas ('envoltura de la mazorca de maíz').

\subsection{0 'Machacar' e instrumentos para moler}

En este apartado se registran los verbos empleados para el acto de machacar, y los instrumentos empleados en ese menester (preguntas 31 y 32). En cuanto a los primeros, casi 
todos los verbos son sinónimos de machacar, tales como: amasar, apachar, aplastar, apretar, deshacer, desquebrajar esquebrajar, destripar estripar, golpear con tetunte, hacer masa, hacer piedra, machacar $\sim$ machucar, majar, martajar, moler, morterear $\sim$ morteriar, picar, quebrantar, quebrar, rallar, triturar. De estos verbos, solamente morterear $\sim$ morteriar es una creación centroamericana; el resto son verbos del español estándar.

Por lo que respecta al segundo punto, se ven dos clases de instrumentos usados para moler: los movidos por medios eléctricos, y los movidos por tracción corporal, particularmente con la mano. Los primeros son: licuadora, molino eléctrico, máquinas de moler y procesador (de alimentos).

Los segundos son los siguientes: metate o piedra de moler, molino de mano, molino de piedra, mortero, piedra (de moler), trapiche y trozo de madera.

\subsection{1 ¿En qué se lavan los platos?}

La pregunta 33 del Cuestionario tuvo como resultado los siguientes datos: por una parte, se citó la máquina eléctrica para lavar la vajilla: lavaplatos, lavatrastos $\sim$ lavatrastes. Por otra parte, la mayor parte de las palabras apuntan a sitios de la cocina dispuestos para tal fin, los cuales son muebles fijos: fregadero $\sim$ fregador, lavadero $\sim$ lavandero $\sim$ lavador, lavamanos, pila, (norte de América Central) poyetón, (Honduras) tablero.

Asimismo, palabras como azafate, balde, batea, paila, (Nicaragua) pana, palangana, platón y tina aluden a recipientes grandes empleados para lavar, los cuales tienen el común denominador de ser portátiles y cóncavos. Por último, hubo gente que afirmó lavar los platos en los ríos o en quebradas (Figura 5).

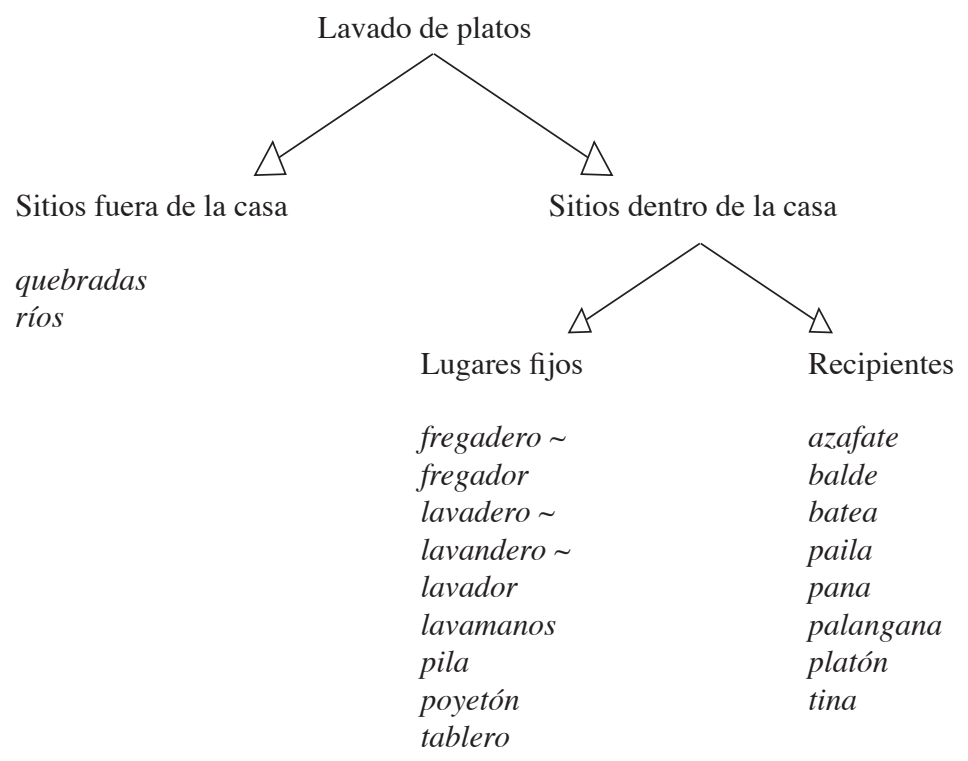

Figura 5. ¿En qué se lavan los platos? 


\subsection{2 ¿Dónde se colocan los platos para que escurra el agua?}

Los medios empleados para secar los platos (pregunta 34 del Cuestionario) son cuatro:

1. Recipientes: Se trata de artefactos cóncavos, muchos de los cuales también se emplean en el lavado de vajilla. Se citan balde, banco, batea, huacal, (Nicaragua) pana, (Panamá) platón. Dos de ellos - canasta, cesta- son fabricados de fibras naturales o plástico y tienen la facultad de ser porosos, por donde se filtra el agua.

2. Muebles fijos: Por lo general son los lugares de la cocina empleados para otras faenas caseras, de entre los cuales están fregadero, lavadero lavandero, lavamanos, lavatrastes, locero, moledero molendero, (Panamá) mostrador, pila, platera y poyetón.

3. Aparatos: Son artefactos construidos casi exclusivamente para dejar que se seque la vajilla, por ejemplo: (Panamá) barbacoa, escurredero $\sim$ escurridero $\sim$ escurridor, estilador, secador, (Panamá) talanquera, trastero (de madera o plástico).

4. Posiciones o estados: En estos casos, no se emplea ningún artefacto o mueble, sino que el aire o la posición de la vajilla son los factores que ayudan a que se seque: embrocados, se dejan ahí.

\subsection{Clases de camas}

Los datos suministrados por los informantes a la pregunta 35 permiten dividirlos en las categorías que se enumeran a continuación, las cuales no siempre son excluyentes, dada la diversidad y los tipos de estructuras con que dichas categorías se pueden combinar.

Según los materiales de que está hecho el armazón de las camas: camón (Costa Rica), cama de aluminio, cama de cabuya, cama de cañablanca, (Panamá) cama de cañaza ${ }^{24}$ cama de carricillo, cama de colchón (el cual puede ser de algodón, espuma o esponja, así como de resortes), cama de cordeles, cama de cuero de res o de vaca, cama de junco (cama junquiada en Nicaragua), cama de hierro, cama de madera, cama de metal, cama de mimbre, cama de pita, cama de palo redondo, (Panamá) cama de quincha, cama de tubo, catre (de metal o de madera).

Por el tipo de soporte o base: camastrón (Guatemala y Honduras), ${ }^{25}$ cama acolchada, cama de cuero, cama de género, cama de lazo, cama de lona, cama de resortes, cama de pita, cama de tablas, cama de tela, somier, tijera $\sim$ tijereta.

Por la cantidad de personas que pueden dormir en ella: Si es para una persona, se les llama cama sencilla, cama unipersonal, cuna o cama de bebé, cama para niño pequeño; y si para dos, tienen los siguientes nombres: cama de dos colchones, cama doble, cama king cama king size, cama matrimonial, cama semimatrimonial.

Por otras funciones: camasofá sofá cama, cama de bastidor, cama sandwich o cama plegable o plegadiza, cama ortopédica, camastro.

Por el modelo: cama capri, cama imperial, cama indufoam, cama luna, cama platina, cama spring, camilla, tijera $\sim$ tijereta (camas sin respaldo).

Por la estructura: colchoneta colchonete, estera, hamaca, petate, tapesco (todas sin patas).

Por la altura: cama de dos pisos, camarote, litera.

\subsection{Clases de cunas}

Al igual que en el apartado anterior, las camas para bebés (pregunta 36 del Cuestionario) pueden dividirse en las siguientes categorías. 
Según los materiales de que están fabricadas: (Honduras) cuna con cacaste ${ }^{26}$ de tablas, cuna de reglitas, cuna de aluminio, cuna de cedazo, cuna de fibra, cuna de hierro, cuna de junco, cuna de lona, cuna de madera, cuna de melamina, cuna de metal, cuna de mimbre, cuna de pita, cuna de plástico.

Con mueble adicional para guardar: cama-cuna o cuna-cama, cuna con gavetas, cuna con mueble, cuna sin gavetas.

Portátiles: coche, corral corralito, encierro, jaba, moisés.

Para mecer al niño: cuna mecedora, hamaca.

\subsection{Arrullar y cantarle al niño para que se duerma}

Los verbos recopilados en estos puntos (preguntas 37 y 38 del Cuestionario) no son todos sinonímicos de arrullar o cantar, sino que tienen que ver con distintos actos, definidos metonímicamente:

a) 'Acostar al niño y hacer que se duerma': acunar, acurrucar, dormir(lo).

b) 'Acariciar al niño': acariciar, arrullar, mimar, ñañequear (Panamá), ñuñuquear (Honduras).

c) 'Hacer que el niño se duerma': adomecer(lo), contemplar(lo), chinchiniar chinchoniar.

d) 'Cubrir al niño para que se acueste': arropar.

e) 'Cargar y menear al niño para que concilie el sueño': cargar, chinear $\sim$ chiniar, entretener, hamaquear jamaquear, mecer, mover, pasear $\sim$ pasiar.

f) 'Cantar al niño para que se duerma': cantar, (Panamá) cumbimbear, arrullar, hacer cucú, hacer arrurrú.

\subsection{Artefacto para hacer caminar a los niños}

Los vocablos reunidos en este punto (pregunta 39) tienen que ver, en términos generales, con un artefacto con ruedas o cosa similar, el cual sirve para que el niño esté sentado y pueda desplazarse sin dificultad. Estos son: andadera $\sim$ andador, (Guatemala) araña, (Honduras) carretía, (Nicaragua) andarivel, (Costa Rica) chino.

Pero no solamente se registraron artefactos; algunos informantes adujeron otros medios para hacer caminar al niño, como es con una soga templada (Panamá) o con un trapo (Honduras) atados a la cintura.

\subsection{7 'Cobijarse' y ropa usada para cubrirse y dormir}

Para la acción de cubrirse el cuerpo con una cobija o manta y espantar el frío (preguntas 40 y 41), se hallaron los siguientes verbos, los cuales aluden a distintas aristas del evento:

a) 'Cubrirse, en general': envolverse, taparse.

b) 'Envolverse con un abrigo o cosa similar': abrigarse, emponcharse, enchamarrarse, (Honduras) embojotarse.

c) 'Echarse una manta o cosa similar': acobijarse cobijarse, arroparse cubrirse con la cobija, echarse (la) cobija, encolcharse, ponerse encima la sábana.

d) 'Contraer el cuerpo': encogerse, enrollarse. 
A la pregunta ¿con qué se cubre uno para dormir?, se obtuvieron dos tipos de datos: aquellos que tienen que ver con mantas o cosa similar, y prendas de vestir.

En cuanto a los primeros, los informantes mencionaron: (El Salvador) chiva, ${ }^{27}$ cobertor, cobija, colcha, cubrecama, cubrecolchón, edredón, frazada, (Costa Rica) manta, sábana y sobrecama.

Respecto de las prendas de vestir, se registraron: camisón, chamarra, piyama y poncho.

\subsection{Muebles en que se guarda la ropa}

Los datos recogidos en la pregunta 42 dan pie para clasificar las palabras en dos grupos principales: muebles en sí (empotrados o movibles), y artefactos. Los artefactos pueden ser de dos clases: piezas y recipientes, generalmente con tapa. Los recipientes, a su vez, se pueden dividir en arcas (muebles de una pieza con tapas y bisagras) y cestería (Figura 6).

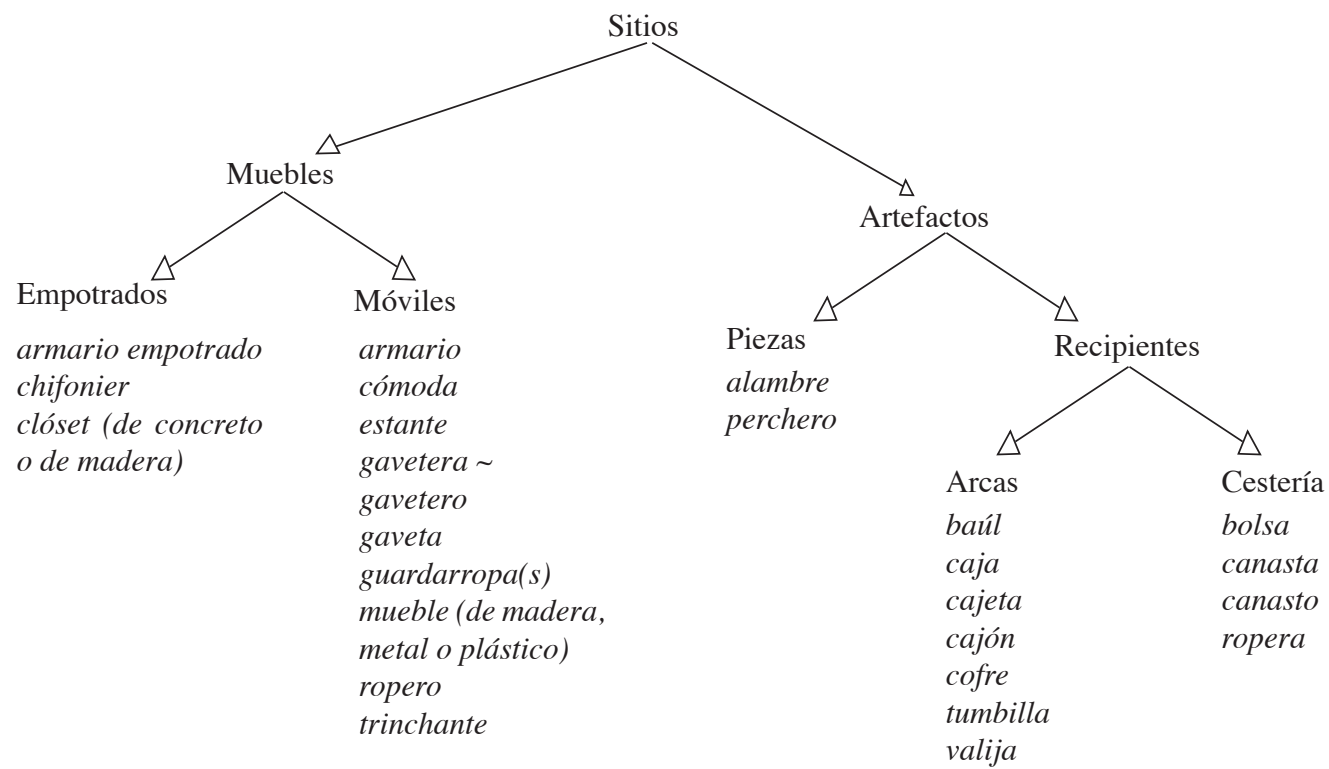

Figura 6. Lugares en que se guarda la ropa

\subsection{Utensilios para alumbrarse en caso de no haber luz eléctrica}

Las palabras que se recogen en este apartado (pregunta 43) se clasifican en cuatro grupos dependiendo de su capacidad o manera de alumbrar:

1. Utensilios de parafina o sebo: candela, este(a)rina, vela, (Panamá) vela de pelman, (Nicaragua) veladora.

2.Utensilios de combustión (gas, queroseno, petróleo): candil, canfinera, carburo, carretero (El Salvador), cóleman, (Panamá) guaricha, lámpara, planta (de gas o de gasolina), quinqué, (Guatemala) velador.

3. Utensilios por medio de baterías: celular, flash light, foco (linterna de batería, manual), lámpara de tubo, lámpara recargable, linterna, reflector.

4.Utensilios vegetales: fogata, mechón, ocote (en mechones). 
El aceite como combustible brilla por su ausencia en los datos analizados, muy probablemente debido a la ausencia de lámparas que funcionen con este líquido oleaginoso.

\section{Extensión geográfica del léxico}

A pesar de que el presente no es un estudio de carácter dialectal, se pueden extraer algunos comentarios en lo relativo a la extensión geográfica del léxico estudiado.

En primer lugar, en los datos analizados se observa que las entradas que se registran en la totalidad de los países encuestados son por lo general palabras provenientes del léxico general, estándar o patrimonial del español. A manera de ejemplo se citan: abanico, abrigarse, acera, acurrucar, adobe, baño, bloque, cajón, cama, canasta, cerradura, cobijarse, cuarto, cuchillo, despensa, dormitorio, habitación, hierro, inodoro, tabla, teja y muchas otras, las cuales mantienen incólume su significado y, por lo tanto, son reconocidas semánticamente en cualquier parte del mundo panhispánico. Frente a este punto es menester actuar con mucha cautela porque, por distintas circunstancias, en varias ocasiones en algunos países no se mencionaron palabras que por lo general pertenecen al patrimonio panhispánico, tales como acariciar (registrada solamente en Costa Rica), acrílico (solo en Panamá), adormecer (Guatemala y Honduras), hogar (señalada en todos los países menos en Costa Rica), sin que lo anterior signifique ausencia de dicho vocablo en el país donde no se registró el vocablo en cuestión. ${ }^{28}$

En segundo lugar, hay palabras que se podrían catalogar como centroamericanismos, pues aparecen como tales en los diccionarios generales de la lengua, o en diccionarios nacionales, y no se registran como de uso panhispánico. Entre estas se pueden señalar: bodega 'lugar para guardar', chinear 'arrullar', enllavar 'cerrar con llave', frazada 'cobija', guacal 'recipiente hecho de la jícara', hamaquear 'arrullar', horcón 'madero vertical que sirve para sostener vigas', hornilla 'estufa para cocinar', interior 'retrete', jaba 'caja', juego de trastes 'vajilla', lavatrastes lavatrastos 'pila de fregar', mediagua o media agua 'construcción con el techo de una sola vertiente', solar 'traspatio', etc.

En tercer lugar, hay palabras que se registran en un solo país, como se puede ver en la siguiente lista, organizada por países de norte a sur:

Guatemala: apachar 'machacar', emponcharse 'cobijarse', hachuela 'cuchillo de cocina', mochuelito 'cuchillo de cocina', piedrín 'material para techo', tayuyo 'tipo de ladrillo', etc.

El Salvador: bodegón 'habitación para guardar enseres', champa 'casa', chele chelebocón 'retrete', encolcharse 'cobijarse', guardaplatos 'armario para la vajilla', reverbero 'tipo de cocina', etc.

Honduras: cacaste 'utensilio para colgar', canapo 'palo de la techumbre', chola 'casa', embajotarse 'cobijarse', guardacomida 'alacena', locero 'lugar para guardar la vajilla', tetunte 'piedra que forma el fogón', tique 'tipo de hoja para techar', etc.

Nicaragua: abuelita 'mecedora', chinchonear 'mover la cuna para arrullar', cumbita cumbito 'recipiente para beber', pata de gallina 'tipo de silla', etc.

Costa Rica: canfinera 'linterna', cuarto de pilas 'aposento para lavar', cutacha 'tipo de cuchillo', pachuco 'tipo de techo', zócalo 'tipo de construcción de casa', etc.

Panamá: bohío 'casa', cajeta 'caja', carriola 'vara de metal para la construcción', guardera 'mueble para preservar alimentos', guaricha 'linterna', jorón 'habitación', pato loco 'tipo de asiento', quincha 'hoja para techos', etc. 
En cuarto lugar, hay algunos casos donde se notan diferencias geográficas debido a la división de la palabra según su constitución fonética o morfología: butaca en Guatemala y Costa Rica, pero butaco en Honduras y Nicaragua; tapanco en Guatemala, pero tabanco en El Salvador y Costa Rica; tenamaste en Guatemala, pero tinamaste en Costa Rica, chavín en Honduras, pero llavín en Costa Rica, ñuñuquear en Nicaragua, pero ñiañequear en Panamá, etc.

Fuera de algunas palabras que se registran únicamente en Panamá, y que la unen con países de América del Sur (por ejemplo guaricha, quincha, tagua, totuma), es casi imposible determinar una distribución del léxico condicionada por zonas dialectales, ya que el léxico se puede presentar, con las excepciones anteriores, en diferentes puntos del Istmo Centroamericano, sin que ello signifique distinción dialectal. En este caso, habrá que andar con cautela a la hora de establecer de manera más tajante una división geolectal basada en el léxico analizado; de todas maneras, el vocabulario de la vivienda (2852 entradas) representa una ínfima parte del total del léxico recopilado en los atlas lingüísticos centroamericanos $(0,019 \%$ de un total de 150.000 entradas $)$.

\section{Conclusión}

El análisis del léxico de la vivienda según los datos recogidos en los atlas lingüísticos de América Central lleva a afirmar que, en muchos casos, los centroamericanos categorizan el léxico de la vivienda de manera diferente a como se da en el español estándar. Así, muchos de los términos registrados no coinciden en su significado con los términos que se observan español estándar (léase DLE), y a veces se entrecruzan, tal como sucede con la terminología del tejado (cimbra, solera, cercha, caballete, etc.).

La observación anterior deberá tenerse en cuenta a la hora de aplicar una terminología técnica que calce con la terminología popular. A su vez, deberá servir de advertencia para los técnicos cuando se quiera explicar a sus clientes términos que quizás tengan otro significado en la vida diaria.

En lo pertinente a la distribución geográfica de los datos, no es posible extraer ninguna inferencia que dé pie a una división geolectal del español centroamericano sobre la base del léxico de la vivienda. Habrá que esperar a un análisis similar que cubra los demás campos etnosemánticos de que se componen los atlas lingüístico-etnográficos del español centroamericano, para llegar a una conclusión viable.

Queda averiguar, a manera de hipótesis, si el léxico tiende a ser representativo de dos grupos sociales en el Istmo Centroamericano, cuales son la clase media y la clase media-baja, proveniente de barrios o de centros urbanos, y menos de las zonas rurales. Lo anterior se podría justificar en el hecho de que fueron prácticamente de dichas clases sociales de donde provenían los informantes que suministraron el corpus analizado. Por fuera quedaron informantes que provenían de la clase adinerada y de los grupos étnicos minoritarios. ${ }^{29}$

\section{Notas}

1. El proyecto está descrito en: http://www.uib.no/fremmedsprak/forskning/forskingsprosjekt-ved-if/ spraakvariasjon-i-mellom-amerika. Aprovecho para expresar mi agradecimiento a estas dos instituciones por su generosísimo apoyo económico a la presente investigación.

2. Es decir, recopilación de palabras y su ordenamiento alfabético, a modo de diccionario.

3. Grupo étnico que habita la vertiente atlántica de Costa Rica hasta la parte fronteriza de este país con Panamá, y la vertiente pacífica del sur de Costa Rica.

4. Para una amplia discusión acerca del término "cultura", véase Risager (2006). 
5. En el cuestionario original (Quesada-Pacheco, 1992, pp. 30-31) figuran 44 preguntas por un error de imprenta, ya que se pasó de la 21 a la 23.

6. En algunos casos se recogió una palabra hasta siete veces para una sola pregunta.

7. Término registrado en el Atlas de Costa Rica, pero restringido al ambiente jergal; con lo cual, es de uso poco común.

8. La gran mayoría de las personas entrevistadas para la presente investigación provienen de las clases media y baja de los siete países que conforman el Istmo centroamericano.

9. Este apartado une las preguntas 2 y 3 del cuestionario que se aplicó (cfr. Quesada-Pacheco, 1992, p. 30), ya que las respuestas a estos dos puntos quedaron entrelazadas.

10. En Honduras, palmácea cuyas hojas se emplean en techos (Acoelorrhaphe wrightii).

11. Voz recogida en Panamá. Según el DRAE, Tejido o trama de junco con que se afianza un techo o pared de paja, totora, cañas. 2. Pared hecha de cañas, varillas u otra materia semejante, que suele recubrirse de barro y se emplea en cercas, chozas, corrales, etc. Es una palabra usada en la América Meridional.

12. En Panamá, estructura larga de acero galvanizado empleada en la construcción de techos o paredes.

13. También aquí se fusionó esta pregunta con la número 15 del Cuestionario antes mencionado.

14. Además de que la mayor parte de las personas entrevistadas para los atlas centroamericanos vienen de comunidades urbanas, hay que tomar en cuenta que más del 50\% de los centroamericanos viven en centros urbanos (según datos tomados del Consejo Centroamericano de Vivienda y Asentamientos Humanos, 2009, p. 10).

15. En Panamá se registró la variante fonética patiente.

16. Conversación personal.

17. Understanding Media: The Extensions of Man (Gingko Press). Cfr. C. Trilnick (http://proyectoidis.org/ la-comprension-de-los-medios-las-extensiones-del-cuerpo-humano/).

18. Aquí es menester señalar que en muchas zonas rurales del Istmo Centroamericano, particularmente en las más alejadas, pueden verse personas comiendo sin utensilios. Pero también hay ciertos alimentos típicos que deben comerse con las manos o los dedos: empanadas, tortillas, etc.

19. Eufemismo, dado que la palabra cuchara en este país ha tenido un significado sexual ('vagina').

20. El significado panameño de motete 'cesta' difiere del que se emplea en el resto de América Central, donde significa 'fardo, lío'.

21. También conocidas como cocina de tropigás, por la marca registrada de la compañía que lo expende.

22. Según datos obtenidos de http://intcomco.tripod.com/costovida.html.

23. En Panamá se registró contratapadera, pero no figura en ninguna parte.

24. Bambú, en Panamá (DRAE en línea).

25. Según Bentley (2001, p. 92), "Cama de madera con cuerdas cruzadas que forman una base para poner un petate o un colchón".

26. Armazón de varas que sirve de soporte o asiento.

27. De acuerdo con M. Romero (2005, p. 148), es una cobija o colcha de lana.

28. Bastaría hacer una búsqueda electrónica en los sitios pertenecientes a esos países donde no se registra el vocablo en cuestión, para darse cuenta de que se emplean, a pesar de no haberse registrado en los atlas.

29. La hipótesis se podría fundamentar, además, en que cierta cantidad de rubros léxicos se refieren a objetos de poco valor, empleados para guardar o almacenar (por ejemplo: bolsas, cajas, cajones, baúles, etc.) o alimentos (cestos, bolsas, ollas, palanganas, etc.), lo cual da a entender el nivel de escasez de bienes materiales de los entrevistados, fabricados de manera industrial para tal fin (armarios, roperos, refrigeradoras, etc.).

\section{Bibliografía}

Álvarez-Montalbán, E. (2004). Los ojos en el habla popular. Boletín Nicaragüense de Bibliografía y Documentación. El español hablado en Nicaragua: Nuevos Estudios, 122 (enero-marzo), 89-99. 
Bentley, J. W. (2001). Diccionario campesino hondureño. Revista Ceiba. 42 (2), 79-157.

Chavarría-Úbeda, C. y Rosales-Solís, M. A. (2010). Atlas lingüístico-etnográfico de Nicaragua (ALEN). Managua: PAVSA.

Chavarría-Úbeda, C. y Quesada-Pacheco, M. A. (manuscrito). Atlas lingüístico-etnográfico de Guatemala (ALEG). Morfosintaxis y léxico.

Consejo Centroamericano de Vivienda y Asentamientos Humanos (2009). Estrategia centroamericana de vivienda y asentamientos humanos. San Salvador: CCVAH.

De Granda, G. (1978). Estudios lingüísticos hispánicos, afrohispánicos y criollos. Madrid: Gredos.

Dickeman, M. (1982). Hacia la búsqueda de una relación entre lenguaje y cultura: reflexiones de una lingüista. Revista de Filología y Lingüística de la Universidad de Costa Rica. 8, (1-2), 113-120.

Duranti, A. (1997). Linguistic Anthropology. Cambridge: Cambridge University Press.

Foley, V. W. A. (2002). Anthropological Linguistics. An Introduction. Oxford: Blackwell Publishers.

García, R. (2004). Estructuración de los campos semánticos referentes a las tradiciones religiosas de Nicaragua. Boletín Nicaragüense de Bibliografía y Documentación. El español hablado en Nicaragua: Nuevos Estudios. 122 (enero-marzo), 100-114.

Mayers, M. K. (1997). A Look at Latin American Lifestyles. Dallas, Texas: International Muesum of Cultures.

McLuhan, M. (1964). Understanding Media: The Extensions of Man. Corte Madera, California: Gingko Press.

Mišić-Ilić, B. (2004). Language And Culture Studies-Wonderland Through The Linguistic Looking Glass. Facta Universitatis. 3 (1), 1-15.

Palmer, G. B. (2000). Lingüística cultural. Madrid: Alianza Editorial.

Quesada-Pacheco, M. A. (1992). Atlas lingüístico-etnográfico de Costa Rica. Cuestionario. San José: Editorial Nueva Década.

Quesada-Pacheco, M. A. (2008). El español de América Central ayer, hoy y mañana. Boletín de Filología [Universidad de Chile]. 43, 145-174.

Quesada-Pacheco, M. A. (2010). Atlas lingüístico-etnográfico de Costa Rica (ALECORI). San José: Editorial de la Universidad de Costa Rica.

Quesada-Pacheco, M. A. (2011). El mundo de las creencias populares en América Central: aproximación etnolingüística. Temas Iberoamericanos. (127-154). Medellín/Bergen: Fondo Editorial Universidad Eafit/Universidad de Bergen [Noruega].

Quesada-Pacheco, M.A. (2012). El léxico del vestido en América Central: aproximación etnolingüística. Por D. Corbella, J. Dorta, A. Fajardo, L. Izquierdo, J. Medina y A. Nelsi (Coords.). Lexicografía hispánica del siglo XXI, nuevos proyectos y perspectivas: homenaje al profesor Cristóbal Corrales Zumbado. (485-500). España: Arco Libros.

Riley, P. (2007). Language, Culture and Identity. London/New York: Continuum. 
Rivera-Orellana,E.(2011).Atlas lingüístico-etnográfico de El Salvador (ALPES).Morfosintaxis y léxico. San Salvador: UCA.

Rivera-Orellana, E. (2013). Atlas lingüístico-etnográfico de Belice (ALEB). Morfosintaxis y léxico. San Salvador: UCA.

Risager, K. (2006). Language and Culture. Global Flows and Local Complexity. Clevedon/ Buffalo/Toronto: Multilingual Matters LTD.

Romero, M. (2005). Diccionario de salvadoreñismos. San Salvador: Editorial Delgado.

Tinoco-Rodríguez, T. S. (2010). Atlas lingüístico-etnográfico de Panamá (ALEP). Niveles morfosintáctico y léxico. Panamá: Imprenta de la Universidad de Panamá.

Trilnick, C. (s. f). La comprensión de los medios: Las extensiones del cuerpo humano. http:// proyectoidis.org/la-comprension-de-los-medios-las-extensiones-del-cuerpo-humano/ [Consulta 30 de junio de 2015].

Underhill, J. (2012). Ethnolinguistics and Cultural Concepts: Truth, Love, Hate and War. New York: Cambridge University Press.

Ventura, J. (2013). Atlas lingüístico etnográfico de Honduras (ALEH). Nivel léxico. Tegucigalpa: Editorial de la Universidad Nacional Autónoma de Honduras.

Wande, B. (2003). El habla nicaragüense: raíces y creatividad. Lengua. Boletín de la Academia Nicaragüense de la Lengua. 2 (26), 81-124.

\section{Anexo. Cuestionario. La vivienda}

1. casa

2. materiales más comunes de que están construidas las casas de la comunidad

3. materiales de los techos

4. nombres de los tipos de techo

5. solera

6. palo que va de un extremo al otro de la techumbre

7. armazón triangular sobre apoyos

8. maderos sobre la armadura del tejado donde se clavan las tejas o láminas de zinc

9. distribución de las casas

10. grada ante la puerta de la calle

11. cierre de una puerta al que se puede echar la llave

12. cerrar con llave

13. palo que a veces se pone detrás de la puerta, para cerrar

14. habitación en la que se duerme

15. habitación usada para guardar cosas viejas

16. parte descubierta detrás de la casa, con árboles frutales

17. retrete

18. clases y formas de los asientos

19. conjunto de platos, vasos, etc. (¿qué se entiende por vajilla?)

20. muebles o sitios en que se guardan los víveres

21. muebles de cocina donde se preparan los alimentos antes de cocinarlos 
22. muebles o sitios en que se guardan vasos, tazas, platos, etc.

23. utensilio con que se come

24. utensilio en que se bebe

25. cuchillo de cocina

26. cuchillo de mesa

27. utensilios colgantes para preservar alimentos

28. tipos de cocinas

29. piedras del fogón

30. instrumentos para avivar el fuego

31. instrumentos para moler

32. machacar

33. ¿en qué se lavan los platos?

34. ¿dónde se colocan los platos para que escurra el agua?

35. clases de camas

36. clases de cunas

37. mover la cuna o los brazos para que el niño se duerma

38. cantar al niño para que se duerma

39. artefacto para hacer caminar a los niños

40. cobijarse

41. ¿con qué se cubre uno para dormir?

42. muebles en que se guarda la ropa

43. utensilios para alumbrarse en caso de no haber luz eléctrica 